\title{
Natural Tolerance to Ischemia and Hypoxemia in Diving Mammals: A Review
}

\author{
Kaitlin N. Allen and José Pablo Vázquez-Medina* \\ Department of Integrative Biology, University of California Berkeley, Berkeley, CA, United States
}

\section{OPEN ACCESS}

Edited by:

Tatum S. Simonson,

University of California, San Diego,

United States

Reviewed by:

Paul Ponganis,

University of California, San Diego, United States

Randall William Davis,

Texas A\&M University at Galveston, United States

*Correspondence: José Pablo Vázquez-Medina jpv-m@berkeley.edu

Specialty section:

This article was submitted to Integrative Physiology, a section of the journal

Frontiers in Physiology

Received: 24 March 2019 Accepted: 03 September 2019 Published: 20 September 2019

Citation:

Allen KN and Vázquez-Medina JP

(2019) Natural Tolerance to Ischemia and Hypoxemia in Diving Mammals: A Review.

Front. Physiol. 10:1199.

doi: 10.3389/fphys.2019.01199
Reperfusion injury follows ischemia/reperfusion events occurring during myocardial infarction, stroke, embolism, and other peripheral vascular diseases. Decreased blood flow and reduced oxygen tension during ischemic episodes activate cellular pathways that upregulate pro-inflammatory signaling and promote oxidant generation. Reperfusion after ischemia recruits inflammatory cells to the vascular wall, further exacerbating oxidant production and ultimately resulting in cell death, tissue injury, and organ dysfunction. Diving mammals tolerate repetitive episodes of peripheral ischemia/reperfusion as part of the cardiovascular adjustments supporting long duration dives. These adjustments allow marine mammals to optimize the use of their body oxygen stores while diving but can result in selectively reduced perfusion to peripheral tissues. Remarkably, diving mammals show no apparent detrimental effects associated with these ischemia/reperfusion events. Here, we review the current knowledge regarding the strategies marine mammals use to suppress inflammation and cope with oxidant generation potentially derived from diving-induced ischemia/reperfusion.

Keywords: hypoxia, cetacean, pinniped, oxidative stress, inflammation

\section{INTRODUCTION}

The ability to manage body oxygen stores in the face of environmental hypoxia constrains the life history of many vertebrate taxa. In humans, oxygen management is critically important in clinical settings where both acute and chronic conditions such as organ transplantation and intermittent hypoxia contribute to ischemic injuries. Diving mammals, however, experience fluctuations in blood flow and oxygen saturation without sustaining such injuries. A range of physiological mechanisms for coping with finite oxygen availability has been identified to date (for recent comprehensive reviews on the topic, see Davis, 2014; Blix, 2018; Ponganis, 2019). The first - and perhaps most straightforward - of these mechanisms is increased mass-specific body oxygen stores which delay the onset of hypoxemia and tissue hypoxia and prolong submergence times (Ponganis et al., 1993; Kanatous et al., 1999, 2002; Burns et al., 2007). Similarly, splenic contraction increases circulating oxygen levels during apnea in pinnipeds (Castellini and Castellini, 1993; Elsner, 1995; Hurford et al., 1996; Thornton et al., 2001). Populations of human breath-hold divers also demonstrate enlarged spleens and positive selection of genes implicated in spleen size (PDE10A) and regulation of vasomotor tone (BDKRB2) (Hurford et al., 1990; Ilardo et al., 2018). In marine mammals these "onboard" oxygen stores are likely sufficient to support normal aerobic function in peripheral organs including the liver and kidneys during most dives (Davis et al., 1983). Additionally, the majority of pinniped 
dives occur within the aerobic dive limit (Kooyman et al., 1983; Davis and Kanatous, 1999; Davis, 2014). However, diving mammals experience hypoxemia during routine breath holding within aerobic limits, tolerating lower arterial and venous oxygen saturations than most terrestrial mammals including humans (Ferretti et al., 1991; Stockard et al., 2007; Ponganis et al., 2008; Lindholm and Lundgren, 2009; Meir et al., 2009, 2013; McDonald and Ponganis, 2013; Tift et al., 2018). The specific molecular and cellular pathways that protect marine mammals from injuries driven by fluctuations in blood flow and local oxygen tensions remain largely unexplored.

In humans, hypoxemia induces cell death and tissue injury via inflammatory, necrotic, and apoptotic pathways (Gottlieb et al., 1994; Saikumar et al., 1998; Li and Jackson, 2002; Sendoel and Hengartner, 2014). Limited oxygen availability during hypoxia impairs mitochondrial respiration, leading to a drop in intracellular ATP levels. Reoxygenation after hypoxia increases oxidant generation from enzymatic systems (e.g., xanthine oxidase, NADPH oxidases) and mitochondria, carrying an additional threat of oxidative injury to cells and tissues and potentially compromising organismal health and survival (Figure 1; McCord, 1985; Kalogeris et al., 2012). Reperfusion injuries are well documented in humans, particularly with respect to myocardial infarction, ischemic stroke, and organ transplantation (Yellon and Hausenloy, 2007; Iadecola and Anrather, 2011; Salvadori et al., 2015). Thus, both hypoxemia and reduced peripheral perfusion associated with diving can potentially contribute to inflammation and oxidative stress in diving mammals. Remarkably, diving mammals appear to tolerate such conditions without injury. Therefore, understanding the mechanisms underlying this tolerance may yield insight into translational applications for human health.

\section{THE MAMMALIAN DIVING RESPONSE, ISCHEMIA, AND HYPOXIA}

The mammalian diving response consists of several coordinated physiological adjustments originally considered to protect the hypoxia-sensitive central nervous system while oxygen availability is limited during a dive (Irving, 1938; Irving et al., 1941, 1942; Bron et al., 1966). More recently, it was discovered that the diving response also maximizes the aerobic dive limit without compromising central nervous system function (Davis and Kanatous, 1999; Davis, 2014). The three primary components of the diving response are apnea, bradycardia, and peripheral vasoconstriction; all three have been studied in multiple marine mammal species using different experimental approaches (Elsner, 1999; Davis and Williams, 2012; Williams et al., 2015; Blix, 2018; Ponganis, 2019). In pinnipeds, apnea alone is sufficient to induce both bradycardia and vasoconstriction independent of whether the animal is diving (Andrews et al., 1997; Ponganis et al., 2008); bradycardia is further modulated by water temperature, extent of facial submersion, cognition (i.e., anticipation) and exercise (Ridgway et al., 1975; Davis and Kanatous, 1999; Davis and Williams, 2012; Williams et al., 2015; Elmegaard et al., 2016; Kaczmarek et al., 2018). Peripheral perfusion and vasoconstriction have historically been difficult to measure in marine mammals. Early forced submersion studies in Weddell seals indicated an extensive, profound, nearcessation of blood flow to peripheral tissues including the kidney, liver, and spleen during forced dives (Zapol et al., 1979). Similarly, comparative studies showed that seal kidneys exposed to ex vivo ischemia recovered both blood flow and urine production upon reperfusion, while dog kidneys did not (Halasz et al., 1974). The magnitude of the physiological response occurring in free dives is likely different from that observed during forced submersions (Hill et al., 1987; reviewed in Ponganis et al., 2011). Measurements of peripheral perfusion during voluntary apneas, however, have focused on skeletal muscle rather than splanchnic organs (Guyton et al., 1995; Ponganis et al., 2008); reduced muscle perfusion during sleep apneas and diving allows for utilization of myoglobin-bound oxygen by the muscle (Qvist et al., 1981; Guyton et al., 1995; Meir et al., 2009; Wright and Davis, 2015). A lack of instrumentation has hampered direct observations of splanchnic organ perfusion during free dives. Recently, an overall reduction in blubber hemoglobin concentration and saturation was observed in captive harbor seals voluntarily diving within aerobic limits (McKnight et al., 2019), suggesting reduced perfusion to the periphery during routine dives. Despite reduced cardiac output and peripheral oxygen consumption during diving, however, marine mammals deplete central oxygen stores during routine voluntary dives (Shaffer et al., 1997; Williams et al., 1999; Meir et al., 2009, 2013; McDonald and Ponganis, 2013; Tift et al., 2018). As a result, even continuously perfused tissues such as the brain likely experience reductions in oxygen tension as a result of diving-induced hypoxemia (Elsner et al., 1970; Kerem and Elsner, 1973; McKnight et al., 2019). Elevated neuroglobin levels and selective brain cooling may supplement cerebral oxygen stores while decreasing demand during diving (Odden et al., 1999; Williams et al., 2008; Blix et al., 2010; Schneuer et al., 2012). Moreover, the seal brain is capable of both producing and consuming lactate in vivo (Murphy et al., 1980), and glucose deprivation during hypoxia does not appear to negatively impact neuronal function in seal brain slices, suggesting that the seal brain may tolerate these insults (Czech-Damal et al., 2014; Geiseler et al., 2016). Recent transcriptomic analyses suggest that metabolic shifts and upregulation of several major stress response pathways also help protect the seal brain against hypoxic injury (Fabrizius et al., 2016; Hoff et al., 2017). Thus, understanding the mechanisms that protect the marine mammal brain during diving-induced ischemia/reperfusion can potentially reveal new targets for pharmacological interventions in human brain injury and stroke patients.

\section{CONSEQUENCES OF HYPOXIA AND ISCHEMIA: OXIDANT GENERATION, INFLAMMATION, AND OXIDATIVE STRESS}

The complex mechanisms of ischemic tissue damage have been studied extensively in biomedical models due to their clinical relevance to human conditions including organ transplantation, myocardial infarction, and stroke. Oxygen deprivation during 

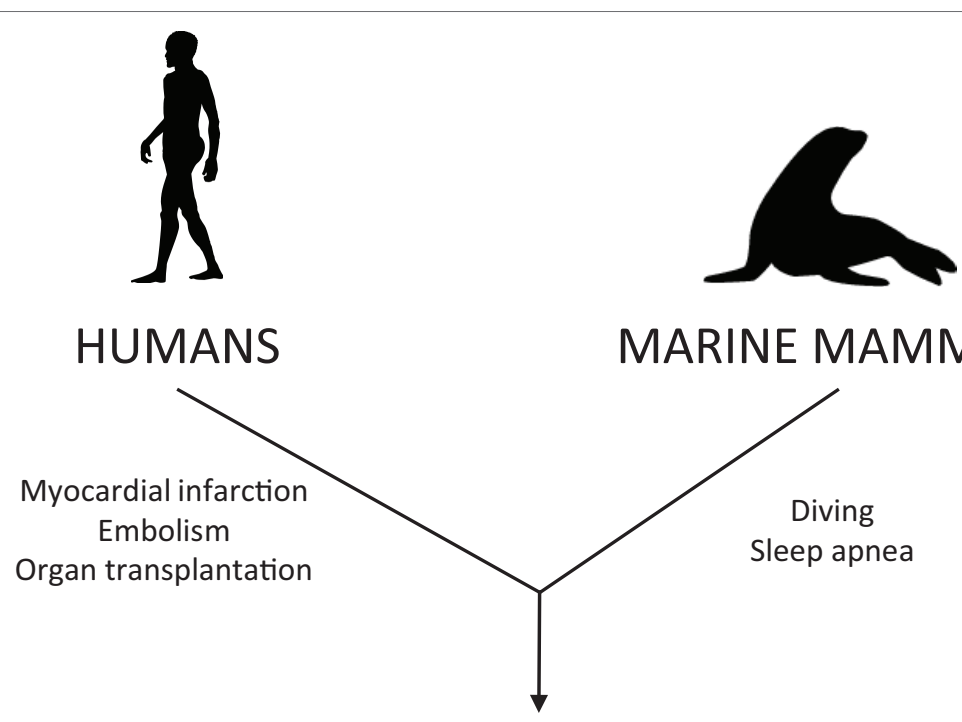

Hypoxemia

Ischemia

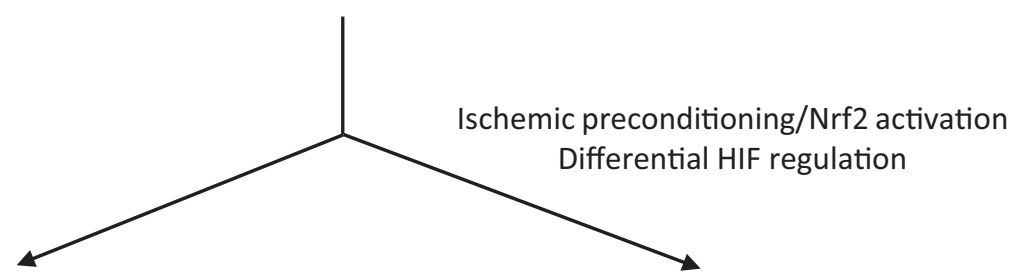

Oxidant generation

Oxidant generation? Inflammatory signaling Limited inflammation

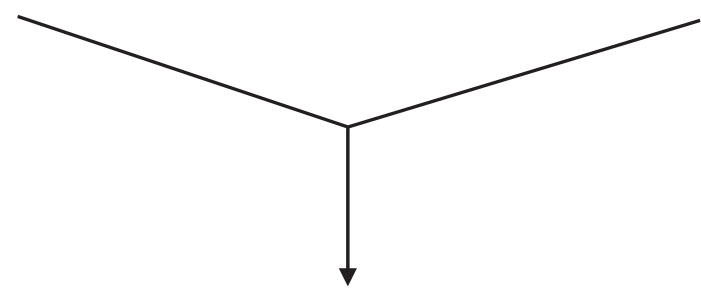

Reperfusion

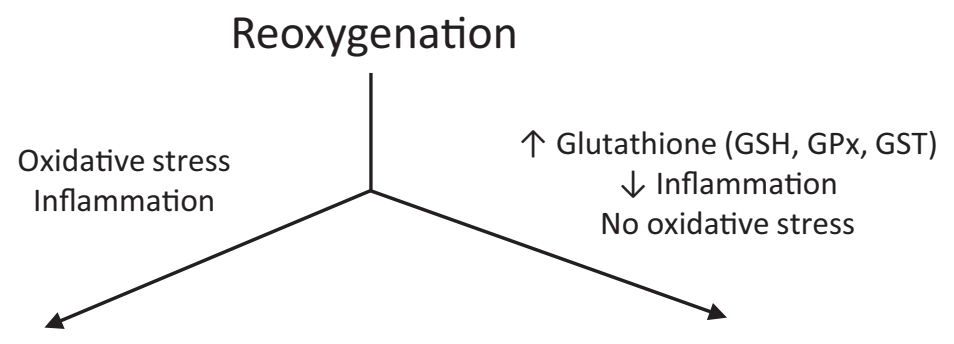

Reperfusion injury

No reperfusion injury

FIGURE 1 | Biochemical mechanisms leading to the prevention of reperfusion injury in diving mammals. Ischemia/reperfusion events are associated with oxidative stress and inflammation in humans but are well tolerated by diving mammals. The mechanisms marine mammals use to prevent inflammation and oxidative stress derived from diving-induced ischemia and hypoxemia are still under investigation but likely include upregulation of genes involved in antioxidant defense and hypoxia tolerance via preconditioning-like responses that involve activation of the transcription factors Nif2 and HIF-1. 
ischemia depletes intracellular ATP; subsequently, ATP degradation products including xanthine and hypoxanthine accumulate (McCord, 1985). Ischemia also dysregulates calcium levels, activating calcium-dependent proteases which cleave xanthine dehydrogenase to generate the active form of the enzyme, xanthine oxidase (Arnould et al., 1992; Berna et al., 2002). Increases in intracellular calcium during ischemic events also induce the activation of NADPH oxidases and promote mitochondrial superoxide radical generation (Brookes et al., 2004; Granger and Kvietys, 2015). Upon reperfusion/reoxygenation, xanthine and hypoxanthine are oxidized by xanthine oxidase, generating superoxide radical and hydrogen peroxide (Chambers et al., 1985; McCord, 1985; Granger, 1988). Similarly, superoxide is generated by reverse electron transport at the mitochondrial complex I during reperfusion (Chouchani et al., 2015). In the vascular endothelium, superoxide generated by NADPH oxidases activated via mechanosignaling during ischemic alterations in shear stress contributes to tissue injury via the formation of peroxynitrite (Beckman et al., 1990; Al-Mehdi et al., 1998; Fisher et al., 2001; Noel et al., 2013; Browning et al., 2014). Furthermore, inflammatory molecules generated or activated by endothelial NADPH oxidase-mediated redox signaling (e.g., CAMs, selectins, NF- $\kappa \mathrm{B}$, and NLRP3 inflammasomes) prime the vasculature for neutrophil adherence and infiltration, promoting further tissue injury during reperfusion (Eltzschig and Eckle, 2011; Iadecola and Anrather, 2011). In diving seals, convective oxygen transport to peripheral tissues remains sufficient to support aerobic metabolism during most dives (Davis et al., 1983; Davis and Kanatous, 1999); however, routine hypoxemia coupled with reoxygenation upon surfacing (Qvist et al., 1986; Meir et al., 2009, 2013; McDonald and Ponganis, 2013; Tift et al., 2018), along with potential alterations in blood flow derived from peripheral vasoconstriction, expose the vascular endothelium to frequent fluctuations in shear and oxygen tension that resemble pathological ischemia/reperfusion events in humans.

Marine mammals do not sustain the reperfusion injuries associated with hypoxemia and ischemia/reperfusion events in humans; however, the mechanisms regulating this oxidant balance in marine mammals remain unclear. Increased purine recycling has been proposed as a mechanism to limit xanthine oxidasederived oxidant generation in marine mammals (López-Cruz et al., 2016), but support for this hypothesis is mixed (SoñanezOrganis et al., 2012; del Castillo Velasco-Martínez et al., 2016). Early work revealed that seal tissues accumulate hypoxanthine after simulated ischemia and are capable of generating oxidants ex vivo (Elsner et al., 1995, 1998; Zenteno-Savín et al., 2002). Similarly, circulating concentrations of xanthine and hypoxanthine increase during spontaneous on-land sleep apneas in elephant seals (Vázquez-Medina et al., 2011d). Moreover, tissue capacity to generate oxidants increases with postnatal maturation in hooded seal skeletal muscle (Vázquez-Medina et al., 2011a), while circulating and muscle levels of xanthine oxidase increase after repetitive sleep apneas in elephant seals (Vázquez-Medina et al., 2011d). In our preliminary observations, we have found that seal endothelial cells in primary culture generate oxidants following exposure to hypoxia/reoxygenation and when incubated with known activators of NADPH oxidases (Vázquez-Medina et al., 2018). Together, these results suggest that avoiding oxidant generation is not a strategy seals use to cope with diving-induced ischemia/reperfusion. Of note is recent evidence showing alterations in the nitric oxide-soluble guanylyl cyclase-cGMP (NO-cGMP) pathway in peripheral tissues of Weddell seals compared to non-diving vertebrates (Hindle et al., 2019) and the previously observed absence of nitric oxide in the exhalate of Weddell seals after voluntary dives (Falke et al., 2008). Such alterations in the NO-cGMP pathway could help maintain differential perfusion during a dive (Hindle et al., 2019) while preventing the formation of peroxynitrite via the reaction of $\mathrm{NO}$ with superoxide generated in response to diving-induced ischemia/ reperfusion (Ischiropoulos et al., 1992; Radi et al., 2001).

Besides their proven role in cell and tissue injury, oxidants participate in essential physiological functions, including host defense and neovascularization (Babior, 1999; Tojo et al., 2005; Browning et al., 2014). Similarly, at sub-toxic levels, oxidants such as hydrogen peroxide, which can be generated directly by xanthine oxidase and certain NADPH oxidases or by dismutation of superoxide, mediate a plethora of redox-dependent pathways related to calcium signaling, protein phosphorylation, and transcription factor activation (Suzuki et al., 1997). Transcription of most antioxidant genes is under control of the nuclear factor E2-related factor 2 ( Nrf2), which is activated in response to temporal increases in intracellular oxidants or other electrophiles (Itoh et al., 1997, 1999). Stimulation of Nrf2 by the lipid peroxidation product 4-hydroxy-2-nonenal (4-HNE) is involved in neuro- and cardio-protection against oxidative stress after ischemic preconditioning (Calvert et al., 2009; Zhang et al., 2010; Bell et al., 2011). In humans, ischemic preconditioning reduces the risk of myocardial injury after coronary artery bypass graft surgery (Thielmann et al., 2013). In elephant seals, repetitive spontaneous sleep apneas result in blood oxygen depletion, reduced muscle blood flow, decreased tissue $\mathrm{P}_{\mathrm{O} 2}$, and increased 4-HNE, nuclear Nrf2 levels, and antioxidant enzyme expression in skeletal muscle (Ponganis et al., 2002, 2006, 2008; Stockard et al., 2007; VázquezMedina et al., 2011d, 2012). These results suggest that repetitive breath holding in marine mammals resembles preconditioning responses that protect tissues from oxidant generation during diving.

\section{COPING WITH DIVING-INDUCED HYPOXIA AND ISCHEMIA: COUNTERACTING OXIDATIVE STRESS AND PREVENTING INFLAMMATION}

High activity and expression of antioxidant enzymes, particularly those related to the glutathione system, have been observed across diving birds and mammals (Murphy and Hochachka, 1981; Corsolini et al., 2001; Wilhelm Filho et al., 2002; Vázquez-Medina et al., 2006, 2007; Zenteno-Savin et al., 2010; García-Castañeda et al., 2017). Baseline circulating and tissue antioxidant levels are higher in diving versus non-diving birds and mammals, supporting the hypothesis that a robust antioxidant defense system mitigates injury from diving-induced oxidant generation in marine vertebrates (Corsolini et al., 2001; Wilhelm Filho et al., 2002; VázquezMedina et al., 2006, 2007, 2012; Zenteno-Savin et al., 2010, 2011; 
García-Castañeda et al., 2017). Whether this relationship between antioxidant levels and diving capacity holds across diving species remains unclear; interspecies comparisons of diving capacity and antioxidant levels are difficult to isolate from confounding speciesspecific life history factors such as fasting and maturation (CantúMedellín et al., 2011; Righetti et al., 2014; Colominas-Ciuró et al., 2017; García-Castañeda et al., 2017). However, in phocid seals, the antioxidant system develops alongside diving capacity during postnatal maturation and does not decline with aging, suggesting a link between diving ability and antioxidant defenses (VázquezMedina et al., 2011b,c; Allen et al., 2019).

Despite strong antioxidant responses, lipid peroxidation has been detected in marine mammal tissues under basal conditions, during aging, and after repetitive apneas (Zenteno-Savín et al., 2002; Vázquez-Medina et al., 2011d, 2012; Allen et al., 2019). Changes in lipid peroxidation levels after oxidant-generating challenges, however, are limited in contrast to what is observed in non-hypoxia tolerant mammals undergoing similar fluctuations in blood flow and tissue oxygenation (Figure 1; Sakamoto et al., 1991; Szabó, 1996; Paradies et al., 1999; Zenteno-Savín et al., 2002; Vázquez-Medina et al., 2007, 2011d; Kalogeris et al., 2012). Consequently, observed lipid peroxidation levels may be within tolerable limits for marine mammals. As discussed above, antioxidant gene expression in marine mammals is likely regulated by redox signaling derived from repetitive apneic periods. Accordingly, sub-lethal levels of oxidants and other potent electrophiles such as lipid peroxidation products (e.g., 4-HNE) may modulate antioxidant gene transcription, contributing to the protective "preconditioning" effect of repeated diving (Zhang et al., 2010; Wang et al., 2018).

In concert with oxidant generation, ischemic inflammation also contributes to reperfusion injury (McCord and Roy, 1982; McCord, 1987; Eltzschig and Carmeliet, 2011; Iadecola and Anrather, 2011). A limited body of recent work has started to address inflammatory responses in diving mammals. Serum from deep-diving seals protected both seal and mouse cells against LPS-induced inflammation in vitro, suggesting an as-yetundetermined anti-inflammatory component in circulation (Bagchi et al., 2018). Similarly, elevated levels of carboxyhemoglobin may protect against inflammatory injury during reperfusion in marine mammals despite detracting from the overall oxygenbinding capacity of the blood (Otterbein et al., 2000; Ozaki et al., 2012; Tift et al., 2014). Thus, diving mammals appear to utilize both anti-inflammatory and antioxidant strategies to mitigate tissue damage potentially derived from diving-induced hypoxemia and ischemia/reperfusion, though the molecular and biochemical bases of this control remain unknown.

Of note is evidence showing that prolonged food deprivation does not increase systemic inflammation but does result in increased muscle TNFa mRNA and protein levels in elephant seals (VázquezMedina et al., 2010; Suzuki et al., 2013). Similarly, breeding haulouts are associated with systemic inflammatory responses in elephant seals, and plasma haptoglobin levels are increased in declining and nutritionally stressed populations of harbor seals and Steller sea lions (Zenteno-Savín et al., 1997; Peck et al., 2016). These results suggest that, rather than being blunted, inflammatory responses in seals are tightly regulated at both systemic and tissue levels and that modulation of these processes may contribute significantly to avoiding diving-induced inflammation. In support of this idea, endocrine manipulation (ACTH stimulation) studies coupled with transcriptomic analyses in elephant seals show suppression of the NF- $\kappa B$ pathway in seal muscle (Khudyakov et al., 2015). Our unpublished observations also suggest regulation of systemic inflammatory components (C-reactive protein levels) in response to both ACTH stimulation and local (muscle) blockade of the glucocorticoid receptor in elephant seals.

\section{MOLECULAR UNDERPINNINGS OF HYPOXIA AND OXIDATIVE STRESS TOLERANCE IN MARINE MAMMALS}

Recent genetic and molecular work has begun to address the underlying gene-level modifications contributing to the physiological adjustments supporting diving in marine mammals. The hypoxia-inducible factor 1 (HIF-1) is considered the master regulator of the molecular response to hypoxia across taxa (Soitamo et al., 2001; Nikinmaa et al., 2004; Semenza, 2008; Weidemann and Johnson, 2008). Functional HIF-1 is composed of two subunits, HIF- $1 \alpha$ and HIF- $1 \beta$. Under normoxic conditions, the pVHL-ubiquitin-proteasome proteolytic pathway continuously degrades HIF-1 $\alpha$. During hypoxia, this degradation is halted and HIF-1 $\alpha$ dimerizes with HIF- $1 \beta$, translocating into the nucleus where it regulates transcription of genes involved in angiogenesis, erythropoiesis, and proliferation (Wang et al., 1995; Lee et al., 2004). Convergent substitutions in the HIF-1 $\alpha$ amino acid sequence across hypoxia-tolerant mammals including cetaceans, high altitude ungulates, and subterranean rodents suggest a critical role for HIF-1a regulation in natural hypoxia tolerance (Zhu et al., 2018). Seals possess a single copy of the HIF-1a gene; it is similar in sequence to terrestrial mammal HIF-1 $\alpha$, though with several amino acid differences in the oxygen-dependent degradation domain (Johnson et al., 2005). Seal tissues with higher HIF-1a protein levels show less overall protein oxidation, suggesting that HIF-1a expression protects against oxidative stress in marine mammals (Johnson et al., 2004). Interestingly, amino acid sequence differences in cetacean HIF-1 1 likely affect HIF-1 $\alpha$ sensitivity and responsiveness to changing oxygen conditions rather than establishing a constitutively active response (Bi et al., 2015). In our in vivo experiments we have observed marked HIF-1a upregulation in elephant seal muscle in response to prolonged fasting and repetitive sleep apneas (Vázquez-Medina et al., 2011d; Soñanez-Organis et al., 2014). Moreover, our preliminary observations suggest that HIF-1a stabilization is rapid and sustained in response to hypoxia in seal endothelial cells in primary culture in comparison to the response observed in human cells. Together, these studies suggest a critical role of HIF-1a in mediating hypoxia tolerance in marine mammals.

Recent phylogenomic studies have begun to uncover additional molecular mechanisms underpinning ischemia/reperfusion tolerance in marine mammals, including the expansion and positive selection of several gene families related to oxidative stress tolerance and oxygen management. Most work has considered cetacean species; pinniped genomes have generally been less available. In strong 
agreement with the current physiological understanding of antioxidants in both cetaceans and pinnipeds, several genes in the glutathione system - including glutathione reductase, glutathione peroxidases, and $\gamma$-glutamylcysteine ligase - are expanded, under positive selection, and/or have amino acid changes in cetaceans (Yim et al., 2014; Zhou et al., 2018). Two peroxiredoxin gene families (PRDX1 and PRDX3) are also expanded in cetacean lineages (Yim et al., 2014; Zhou et al., 2018), suggesting an augmented capacity for redox signaling and antioxidant protection (Perkins et al., 2015). Moreover, an inactivating mutation in the cetacean gene encoding Pol $\mu$, a polymerase with low fidelity in repairing oxidative DNA damage, suggests that reliance on a higher fidelity polymerase $(\operatorname{Pol} \lambda)$ may confer tolerance to oxidative damage (Pryor et al., 2015; Huelsmann et al., 2019). In cetaceans, contracted gene families involved in the acute inflammatory response and repair of lipid peroxidation support physiological data in deep-diving pinnipeds that suggest that these animals may have evolved mechanisms to cope with ischemic inflammation associated with diving (Tift et al., 2014; Bagchi et al., 2018; Meyer et al., 2018; Zhou et al., 2018). Positive, convergent selection for a gene encoding a lung surfactant protein (SFTPB) in cetaceans, pinnipeds, and sirenians could help explain the rapid distribution of pulmonary surfactant necessary to sustain and tolerate repeated lung collapse and re-inflation in diving mammals (Miller et al., 2004, 2006; Spragg et al., 2004; Gutierrez et al., 2015; Chikina et al., 2016).

Managing body oxygen stores and tissue oxygen supply while diving is of paramount importance for marine mammals. Hemoglobin and myoglobin are central to this process; both are under positive selection in cetaceans (Tian et al., 2016). In the case of myoglobin, an augmented net surface charge observed across all diving mammals might allow for high, functional muscle myoglobin concentrations, thereby increasing body oxygen stores (Mirceta et al., 2013). Several metabolic gene families are also under positive selection in cetaceans, including TCA cycle enzymes citrate synthase and pyruvate carboxylase (Tian et al., 2017). Cetacean-specific amino acid changes in and expansion of lactate dehydrogenase and monocarboxylate transporter 1 genes suggest an increased ability to metabolize lactate after dives exceeding aerobic limits (Yim et al., 2014; Tian et al., 2017). Lactate has been increasingly recognized as a primary metabolic fuel rather than a waste product (Hui et al., 2017; Brooks, 2018). Therefore, these observations could help explain why several marine mammals routinely dive beyond their calculated aerobic dive limits and can spend up to $90 \%$ of their time at sea submerged with minimal recovery periods (Le Boeuf et al., 1988; Costa et al., 2001; Butler, 2006; Robinson et al., 2012; Meir et al., 2013).

\section{REFERENCES}

Allen, K. N., Vázquez-Medina, J. P., Lawler, J. M., Mellish, J.-A. E., Horning, M., and Hindle, A. G. (2019). Muscular apoptosis but not oxidative stress increases with old age in a long-lived diver, the Weddell seal. J. Exp. Biol. 222:jeb200246. doi: 10.1242/jeb.200246

Al-Mehdi, A. B., Zhao, G., Dodia, C., Tozawa, K., Costa, K., Muzykantov, V., et al. (1998). Endothelial NADPH oxidase as the source of oxidants in

\section{CONCLUSIONS AND FUTURE DIRECTIONS}

Marine mammals experience diving-induced hypoxemia and ischemia/reperfusion events without apparent detrimental effects. Physiological, biochemical, and genomic studies have begun to uncover the mechanisms underlying such extreme tolerance. Among those mechanisms, coordinated body-wide responses to delay the onset of tissue hypoxia, counteract oxidant generation and prevent inflammation are critical. Convergent genomic changes across marine mammal lineages hint at the evolutionary underpinnings of the physiological adaptations supporting mammalian diving (Chikina et al., 2016). The increasing availability of genome sequences from additional species will certainly strengthen these studies. Functional studies dissecting the cellular and molecular underpinnings that confer tolerance to hypoxia and ischemia in marine mammals are yet to be conducted. We and others are currently carrying out experiments using ex vivo systems that are amenable to physiological manipulation and molecular perturbation in an effort to provide the missing link between genomic- and organismal-level investigations. Identifying the drivers of ischemic and hypoxemic tolerance in marine mammals can provide a mechanistic understanding of natural tolerance to such conditions while aiding in translation to clinical applications.

\section{AUTHOR CONTRIBUTIONS}

KA and JV-M wrote and edited the manuscript.

\section{FUNDING}

This work was supported by UC Berkeley funds. KA is supported by the National Science Foundation Graduate Research Fellowship Program and a UC Berkeley Fellowship. Publication made possible in part by support from the Berkeley Research Impact Initiative (BRII) sponsored by the UC Berkeley Library.

\section{ACKNOWLEDGMENTS}

We thank four anonymous reviewers for their comments and feedback on the manuscript. We also thank Emily Lam and Esmeralda Garcia-Orosco for reading and commenting on the manuscript.

lungs exposed to ischemia or high $\mathrm{K}(+)$. Circ. Res. 83, 730-737. doi: 10.1161/01.RES.83.7.730

Andrews, R. D., Jones, D. R., Williams, J. D., Thorson, P. H., Oliver, G. W., Costa, D. P., et al. (1997). Heart rates of northern elephant seals diving at sea and resting on the beach. J. Exp. Biol. 200, 2083-2095.

Arnould, T., Michiels, C., Alexandre, I., and Remacle, J. (1992). Effect of hypoxia upon intracellular calcium concentration of human endothelial cells. J. Cell. Physiol. 152, 215-221. doi: 10.1002/jcp.1041520127 
Babior, B. M. (1999). NADPH oxidase: an update. Blood 5, 1464-1476.

Bagchi, A., Batten, A. J., Levin, M., Allen, K. N., Fitzgerald, M. L., Hückstädt, L. A., et al. (2018). Intrinsic anti-inflammatory properties in the serum of two species of deep-diving seal. J. Exp. Biol. 221:jeb178491. doi: 10.1242/jeb.178491

Beckman, J. S., Beckman, T. W., Chen, J., Marshall, P. A., and Freeman, B. A. (1990). Apparent hydroxyl radical production by peroxynitrite: implications for endothelial injury from nitric oxide and superoxide. Proc. Nati. Acad. Sci. USA 87, 1620-1624.

Bell, K. F., Al-Mubarak, B., Fowler, J. H., Baxter, P. S., Gupta, K., Tsujita, T., et al. (2011). Mild oxidative stress activates Nrf2 in astrocytes, which contributes to neuroprotective ischemic preconditioning. Proc. Natl. Acad. Sci. USA 108, E1-E2. doi: 10.1073/pnas.1015229108

Berna, N., Arnould, T., Remacle, J., and Michiels, C. (2002). Hypoxia-induced increase in intracellular calcium concentration in endothelial cells: role of the $\mathrm{Na}(+)$-glucose cotransporter. J. Cell. Biochem. 84, 115-131. doi: 10.1002/jcb.1271

Bi, J., Hu, B., Zheng, J., Wang, J., Xiao, W., and Wang, D. (2015). Characterization of the hypoxia-inducible factor 1 alpha gene in the sperm whale, beluga whale, and Yangtze finless porpoise. Mar. Biol. 162, 1201-1213. doi: 10.1007/ s00227-015-2662-4

Blix, A. S. (2018). Adaptations to deep and prolonged diving in phocid seals. J. Exp. Biol. 221:jeb182972. doi: 10.1242/jeb.182972

Blix, A. S., Walløe, L., Messelt, E. B., and Folkow, L. P. (2010). Selective brain cooling and its vascular basis in diving seals. J. Exp. Biol. 213, 2610-2616. doi: 10.1242/jeb.040345

Bron, K. M., Murdaugh, H. V., Millen, J. E., Lenthall, R., Raskin, P., and Robin, E. D. (1966). Arterial constrictor response in a diving mammal. Science 152, 540-543. doi: 10.1126/science.152.3721.540

Brookes, P. S., Yoon, Y., Robotham, J. L., Anders, M. W., and Sheu, S.-S. (2004). Calcium, ATP, and ROS: a mitochondrial love-hate triangle. Am. J. Physiol. Cell Physiol. 287, C817-C833. doi: 10.1152/ajpcell.00139.2004

Brooks, G. A. (2018). The science and translation of lactate shuttle theory. Cell Metab. 27, 757-785. doi: 10.1016/j.cmet.2018.03.008

Browning, E., Wang, H., Hong, N., Yu, K., Buerk, D. G., DeBolt, K., et al. (2014). Mechanotransduction drives post ischemic revascularization through K-ATP Channel closure and production of reactive oxygen species. Antioxid. Redox Signal. 20, 872-886. doi: 10.1089/ars.2012.4971

Burns, J. M., Lestyk, K. C., Folkow, L. P., Hammill, M. O., and Blix, A. S. (2007). Size and distribution of oxygen stores in harp and hooded seals from birth to maturity. J. Comp. Physiol. B Biochem. Syst. Environ. Physiol. 177, 687-700. doi: 10.1007/s00360-007-0167-2

Butler, P. J. (2006). Aerobic dive limit. What is it and is it always used appropriately? Comp. Biochem. Physiol. A Mol. Integr. Physiol. 145, 1-6. doi: 10.1016/j.cbpa.2006.06.006

Calvert, J. W., Jha, S., Gundewar, S., Elrod, J. W., Ramachandran, A., Pattillo, C. B., et al. (2009). Hydrogen sulfide mediates cardioprotection through Nrf2 signaling. Circ. Res. 105, 365-374. doi: 10.1161/CIRCRESAHA.109.199919

Cantú-Medellín, N., Byrd, B., Hohn, A., Vázquez-Medina, J. P., and Zenteno-Savín, T. (2011). Differential antioxidant protection in tissues from marine mammals with distinct diving capacities. Shallow/short vs. deep/long divers. Comp. Biochem. Physiol. A Mol. Integr. Physiol. 158, 438-443. doi: 10.1016/j.cbpa.2010.11.029

Castellini, J. M., and Castellini, M. A. (1993). Estimation of splenic volume and its relationship to long-duration apnea in seals. Physiol. Zool. 66, 619-627. doi: 10.1086/physzool.66.4.30163811

Chambers, D. E., Parks, D. A., Patterson, G., Roy, R., McCord, J. M., Yoshlda, S., et al. (1985). Xanthine oxidase as a source of free radical damage in myocardial ischemia. J. Mol. Cell. Cardiol. 17, 145-152. doi: 10.1016/S0022-2828(85)80017-1

Chikina, M., Robinson, J. D., and Clark, N. L. (2016). Hundreds of genes experienced convergent shifts in selective pressure in marine mammals. Mol. Biol. Evol. 33, 2182-2192. doi: 10.1093/molbev/msw112

Chouchani, E. T., Pell, V. R., James, A. M., Work, L. M., Saeb-Parsy, K., Frezza, C., et al. (2015). A unifying mechanism for mitochondrial superoxide production during ischemia-reperfusion injury. Cell Metab. 23, 254-263. doi: 10.1016/j.cmet.2015.12.009

Colominas-Ciuró, R., Santos, M., Coria, N., and Barbosa, A. (2017). Reproductive effort affects oxidative status and stress in an Antarctic penguin species: an experimental study. PLoS One 12:e0177124. doi: 10.1371/journal.pone.0177124

Corsolini, S., Nigro, M., Olmastroni, S., Focardi, S., and Regoli, F. (2001). Susceptibility to oxidative stress in Adélie and emperor penguin. Polar Biol. 24, 365-368. doi: 10.1007/s003000000220
Costa, D. P., Gales, N. J., and Goebel, M. E. (2001). Aerobic dive limit: how often does it occur in nature? Comp. Biochem. Physiol. A Mol. Integr. Physiol. 129, 771-783. doi: 10.1016/S1095-6433(01)00346-4

Czech-Damal, N. U., Geiseler, S. J., Hoff, M. L. M., Schliep, R., Ramirez, J. M., Folkow, L. P., et al. (2014). The role of glycogen, glucose and lactate in neuronal activity during hypoxia in the hooded seal (Cystophora cristata) brain. Neuroscience 275, 374-383. doi: 10.1016/j.neuroscience.2014.06.024

Davis, R. W. (2014). A review of the multi-level adaptations for maximizing aerobic dive duration in marine mammals: from biochemistry to behavior. J. Comp. Physiol. B Biochem. Syst. Environ. Physiol. 184, 23-53. doi: 10.1007/ s00360-013-0782-z

Davis, R. W., Castellini, M. A., Kooyman, G. L., and Maue, R. (1983). Renal glomerular filtration rate and hepatic blood flow during voluntary diving in Weddell seals. Am. J. Physiol. Integr. Comp. Physiol. 245, R743-R748. doi: 10.1152/ajpregu.1983.245.5.R743

Davis, R. W., and Kanatous, S. B. (1999). Convective oxygen transport and tissue oxygen consumption in Weddell seals during aerobic dives. J. Exp. Biol. 202, 1091-1113. Available at: http://www.ncbi.nlm.nih.gov/pubmed/ 10101108

Davis, R. W., and Williams, T. M. (2012). The marine mammal dive response is exercise modulated to maximize aerobic dive duration. J. Comp. Physiol. A Neuroethol. Sens. Neural Behav. Physiol. 198, 583-591. doi: 10.1007/ s00359-012-0731-4

del Castillo Velasco-Martínez, I., Hernández-Camacho, C. J., Méndez-Rodríguez, L. C., and Zenteno-Savín, T. (2016). Purine metabolism in response to hypoxic conditions associated with breath-hold diving and exercise in erythrocytes and plasma from bottlenose dolphins (Tursiops truncatus). Comp. Biochem. Physiol. A Mol. Integr. Physiol. 191, 196-201. doi: $10.1016 /$ j.cbpa.2015.10.021

Elmegaard, S. L., Johnson, M., Madsen, P. T., and McDonald, B. I. (2016). Cognitive control of heart rate in diving harbor porpoises. Curr. Biol. 26, R1175-R1176. doi: 10.1016/j.cub.2016.10.020

Elsner, R. (1995). Splenic oxygen storage and blood viscosity in seals. Mar. Mamm. Sci. 11, 93-96. doi: 10.1111/j.1748-7692.1995.tb00278.x

Elsner, R. (1999). "Living in water: solutions to physiological problems" in Biology of marine mammals. eds. J. E. I. Reynolds, and S. A. Rommel (Washington: Smithsonian Institution Press)

Elsner, R., Øyasæter, S., Almaas, R., and Saugstad, O. D. (1998). Diving seals, ischemia-reperfusion and oxygen radicals. Comp. Biochem. Physiol. A Mol. Integr. Physiol. A 119, 975-980. doi: 10.1016/S1095-6433(98)00012-9

Elsner, R., Øyasæter, S., Saugstad, O. D., and Blix, A. (1995). "Seal adaptations for long dives: recent studies of ischemia and oxygen radicals," in Whales, seals, fish and man. eds. A. S. Blix, L. Walloe, and O. Ultang (Elsevier), 371-376.

Elsner, R., Shurley, J. T., Hammond, D. D., and Brooks, R. E. (1970). Cerebral tolerance to hypoxemia in asphyxiated Weddell seals. Respir. Physiol. 9, 287-297. doi: 10.1016/0034-5687(70)90077-0

Eltzschig, H. K., and Carmeliet, P. (2011). Hypoxia and inflammation. N. Engl. J. Med. 364, 656-665. doi: 10.1056/NEJMra0910283

Eltzschig, H. K., and Eckle, T. (2011). Ischemia and reperfusion-from mechanism to translation. Nat. Med. 17, 1391-1401. doi: 10.1038/nm.2507

Fabrizius, A., Hoff, M. L. M., Engler, G., Folkow, L. P., and Burmester, T. (2016). When the brain goes diving: transcriptome analysis reveals a reduced aerobic energy metabolism and increased stress proteins in the seal brain. BMC Genomics 17:11. doi: 10.1186/s12864-016-2892-y

Falke, K. J., Busch, T., Hoffman, O., Liggins, G. C., Liggins, J., Mohnhaupt, R., et al. (2008). Breathing pattern, $\mathrm{CO}_{2}$ elimination and the absence of exhaled NO in freely diving Weddell seals. Respir. Physiol. Neurobiol. 162, 85-92. doi: 10.1016/j.resp.2008.04.007

Ferretti, G., Costa, M., Ferrigno, M., Grassi, B., Marconi, C., Lundgren, C. E. G., et al. (1991). Alveolar gas composition and exchange during deep breathhold diving and dry breath holds in elite divers. J. Appl. Physiol. 70, 794-802. doi: 10.1152/jappl.1991.70.2.794

Fisher, A. B., Chien, S., Barakat, A. I., and Nerem, R. M. (2001). Endothelial cellular response to altered shear stress. Am. J. Physiol. Cell. Mol. Physiol. 281, L529-L533. doi: 10.1152/ajplung.2001.281.3.L529

García-Castañeda, O., Gaxiola-Robles, R., Kanatous, S., and Zenteno-Savín, T. (2017). Circulating glutathione concentrations in marine, semiaquatic, and terrestrial mammals. Mar. Mamm. Sci. 33, 738-747. doi: 10.1111/mms.12391 
Geiseler, S. J., Larson, J., and Folkow, L. P. (2016). Synaptic transmission despite severe hypoxia in hippocampal slices of the deep-diving hooded seal. Neuroscience 334, 39-46. doi: 10.1016/j.neuroscience.2016.07.034

Gottlieb, R. A., Burleson, K. O., Kloner, R. A., Babior, B. M., and Engler, R. L. (1994). Reperfusion injury induces apoptosis in rabbit cardiomyocytes. J. Clin. Invest. 94, 1621-1628. doi: 10.1172/JCI117504

Granger, D. N. (1988). Role of xanthine oxidase and granulocytes in ischemiareperfusion injury. Am. J. Physiol. Heart Circ. Physiol. 255, H1269-H1275. doi: 10.1152/ajpheart.1988.255.6.H1269

Granger, D. N., and Kvietys, P. R. (2015). Reperfusion injury and reactive oxygen species: the evolution of a concept. Redox Biol. 6, 524-551. doi: 10.1016/j.redox.2015.08.020

Gutierrez, D. B., Fahlman, A., Gardner, M., Kleinhenz, D., Piscitelli, M., Raverty, S., et al. (2015). Phosphatidylcholine composition of pulmonary surfactant from terrestrial and marine diving mammals. Respir. Physiol. Neurobiol. 211, 29-36. doi: 10.1016/j.resp.2015.02.004

Guyton, G. P., Stanek, K. S., Schneider, R. C., Hochachka, P. W., Hurford, W. E., Zapol, D. G., et al. (1995). Myoglobin saturation in free-diving Weddell seals. J. Appl. Physiol. 79, 1148-1155. doi: 10.1152/jappl.1995.79.4.1148

Halasz, N. A., Elsner, R., Garvie, R. S., and Grotke, G. T. (1974). Renal recovery from ischemia: a comparative study of harbor seal and dog kidneys. Am. J. Phys. 227, 1331-1335. doi: 10.1152/ajplegacy.1974.227.6.1331

Hill, R. D., Schneider, R. C., Liggins, G. C., Schuette, A. H., Elliott, R. L., Guppy, M., et al. (1987). Heart rate and body temperature during free diving of Weddell seals. Am. J. Physiol. Integr. Comp. Physiol. 253, R344-R351. doi: 10.1152/ajpregu.1987.253.2.R344

Hindle, A. G., Allen, K. N., Batten, A. J., Hückstädt, L. A., Turner-Maier, J., Schulberg, S. A., et al. (2019). Low guanylyl cyclase activity in Weddell seals: implications for peripheral vasoconstriction and perfusion of the brain during diving. Am. J. Physiol. Regul. Integr. Comp. Physiol. 316, R704-R715. doi: 10.1152/ajpregu.00283.2018

Hoff, M. L. M., Fabrizius, A., Czech-Damal, N. U., Folkow, L. P., and Burmester, T. (2017). Transcriptome analysis identifies key metabolic changes in the hooded seal (Cystophora cristata) brain in response to hypoxia and reoxygenation. PLoS One 12:e0169366. doi: 10.1371/journal.pone.0169366

Huelsmann, M., Hecker, N., Springer, M. S., Gatesy, J., Sharma, V., and Hiller, M. (2019). Genes lost during the transition from land to water in cetaceans highlight genomic changes involved in aquatic adaptations. bioRxiv [Preprint].

Hui, S., Ghergurovich, J. M., Morscher, R. J., Jang, C., Teng, X., Lu, W., et al. (2017). Glucose feeds the TCA cycle via circulating lactate. Nature 551, 115-118. doi: 10.1038/nature24057

Hurford, W. E., Hochachka, P. W., Schneider, R. C., Guyton, G. P., Stanek, K. S., Zapol, D. G., et al. (1996). Splenic contraction, catecholamine release, and blood volume redistribution during diving in the Weddell seal. J. Appl. Physiol. 80, 298-306. doi: 10.1152/jappl.1996.80.1.298

Hurford, W. E., Hong, S. K., Park, Y. S., Ahn, D. W., Shiraki, K., Mohri, M., et al. (1990). Splenic contraction during breath-hold diving in the Korean ama. J. Appl. Physiol. 69, 932-936. doi: 10.1152/jappl.1990.69.3.932

Iadecola, C., and Anrather, J. (2011). The immunology of stroke: from mechanisms to translation. Nat. Med. 17, 796-808. doi: 10.1038/nm.2399

Ilardo, M. A., Moltke, I., Korneliussen, T. S., Cheng, J., Stern, A. J., Racimo, F., et al. (2018). Physiological and genetic adaptations to diving in sea nomads. Cell 173:e15, 569-573. doi: 10.1016/j.cell.2018.03.054

Irving, L. (1938). Changes in the blood flow through the brain and muscles during the arrest of breathing. Am. J. Phys. 122, 207-214.

Irving, L., Scholander, P. F., and Grinnell, S. W. (1941). Significance of the heart rate to the diving ability of seals. J. Cell. Comp. Physiol. 18, 283-297. doi: $10.1002 /$ jcp. 1030180302

Irving, L., Scholander, P. F., and Grinnell, S. W. (1942). The regulation of arterial blood pressure in the seal during diving. Am. J. Phys. 135, 5-8.

Ischiropoulos, H., Zhu, L., and Beckman, J. S. (1992). Peroxynitrite formation from macrophage-derived nitric oxide. Arch. Biochem. Biophys. 298, 446-451. doi: 10.1016/0003-9861(92)90433-W

Itoh, K., Chiba, T., Takahashi, S., Ishii, T., Igarashi, K., Katoh, Y., et al. (1997). An Nrf2/small Maf heterodimer mediates the induction of phase II detoxifying enzyme genes through antioxidant response elements. Biochem. Biophys. Res. Commun. 236, 313-322. doi: 10.1006/bbrc.1997.6943

Itoh, K., Wakabayashi, N., Katoh, Y., Ishii, T., Igarashi, K., Engel, J. D., et al. (1999). Keap1 represses nuclear activation of antioxidant responsive elements by Nrf2 through binding to the amino-terminal Neh2 domain. Genes Dev. 13, 76-86. doi: 10.1101/gad.13.1.76

Johnson, P., Elsner, R., and Zenteno-Savín, T. (2004). Hypoxia-inducible factor in ringed seal (Phoca hispida) tissues. Free Radic. Res. 38, 847-854. doi: $10.1080 / 10715760410001725526$

Johnson, P., Elsner, R., and Zenteno-Savín, T. (2005). Hypoxia-inducible factor 1 proteomics and diving adaptations in ringed seal. Free Radic. Biol. Med. 39, 205-212. doi: 10.1016/j.freeradbiomed.2005.03.008

Kaczmarek, J., Reichmuth, C., McDonald, B. I., Kristensen, J. H., Larson, J., Johansson, F., et al. (2018). Drivers of the dive response in pinnipeds; apnea, submergence or temperature? J. Exp. Biol. 221:jeb176545. doi: 10.1242/jeb.176545

Kalogeris, T., Baines, C. P., Krenz, M., and Korthuis, R. J. (2012). Cell biology of ischemia/reperfusion injury. Int. Rev. Cell Mol. Biol. 298, 229-317. doi: 10.1016/B978-0-12-394309-5.00006-7

Kanatous, S. B., Davis, R. W., Watson, R., Polasek, L., Williams, T. M., and Mathieu-Costello, O. (2002). Aerobic capacities in the skeletal muscles of Weddell seals: key to longer dive durations? J. Exp. Biol. 205, 3601-3608

Kanatous, S. B., DiMichele, L. V., Cowan, D. F., and Davis, R. W. (1999). High aerobic capacities in the skeletal muscles of pinnipeds: adaptations to diving hypoxia. J. Appl. Physiol. 86, 1247-1256. doi: 10.1152/ jappl.1999.86.4.1247

Kerem, D., and Elsner, R. (1973). Cerebral tolerance to asphyxial hypoxia in the harbor seal. Respir. Physiol. 19, 188-200. doi: 10.1016/0034-5687(73)90077-7

Khudyakov, J. I., Champagne, C. D., Preeyanon, L., Ortiz, R. M., and Crocker, D. E. (2015). Muscle transcriptome response to ACTH administration in a freeranging marine mammal. Physiol. Genomics 47, 318-330. doi: 10.1152/ physiolgenomics.00030.2015.-While

Kooyman, G. L., Castellini, M. A., Davis, R. W., and Maue, R. A. (1983). Aerobic diving limits of immature Weddell seals. J. Comp. Physiol. B Biochem. Syst. Environ. Physiol. 151, 171-174. doi: 10.1007/BF00689915

Le Boeuf, B. J., Costa, D. P., Huntley, A. C., and Feldkamp, S. D. (1988). Continuous, deep diving in female northern elephant seals, Mirounga angustirostris. Can. J. Zool. 66, 446-458. doi: 10.1139/z88-064

Lee, J.-W., Bae, S.-H., Jeong, J.-W., Kim, S.-H., and Kim, K.-W. (2004). Hypoxiainducible factor (HIF-1)a: its protein stability and biological functions. Exp. Mol. Med. 36, 1-12. doi: 10.1038/emm.2004.1

Li, C., and Jackson, R. M. (2002). Reactive species mechanisms of cellular hypoxia-reoxygenation injury. Am. J. Physiol. Cell Physiol. 282, C227-C241. doi: 10.1152/ajpcell.00112.2001

Lindholm, P., and Lundgren, C. E. G. (2009). The physiology and pathophysiology of human breath-hold diving. J. Appl. Physiol. 106, 284-292. doi: 10.1152/ japplphysiol.90991.2008

López-Cruz, R. I., Crocker, D. E., Gaxiola-Robles, R., Bernal, J. A., Real-Valle, R. A., Lugo-Lugo, O., et al. (2016). Plasma hypoxanthine-guanine phosphoribosyl transferase activity in bottlenose dolphins contributes to avoiding accumulation of non-recyclable purines. Front. Physiol. 7:213. doi: 10.3389/fphys.2016.00213

McCord, J. M. (1985). Oxygen-derived free radicals in postischemic tissue injury. N. Engl. J. Med. 312, 159-163. doi: 10.1056/NEJM198501173120305

McCord, J. M. (1987). Oxygen-derived radicals: a link between reperfusion injury and inflammation. Fed. Proc. 46, 2402-2406

McCord, J. M., and Roy, R. S. (1982). The pathophysiology of superoxide: roles in inflammation and ischemia. Can. J. Physiol. Pharmacol. 60, 1346-1352. doi: $10.1139 / \mathrm{y} 82-201$

McDonald, B. I., and Ponganis, P. J. (2013). Insights from venous oxygen profiles: oxygen utilization and management in diving California Sea lions. J. Exp. Biol. 216, 3332-3341. doi: 10.1242/jeb.085985

McKnight, J. C., Bennett, K. A., Bronkhorst, M., Russell, D. J. F., Balfour, S., Milne, R., et al. (2019). Shining new light on mammalian diving physiology using wearable near-infrared spectroscopy. PLoS Biol. 17:e3000306. doi: 10.1371/journal.pbio.3000306

Meir, J. U., Champagne, C. D., Costa, D. P., Williams, C. L., and Ponganis, P. J. (2009). Extreme hypoxemic tolerance and blood oxygen depletion in diving elephant seals. Am. J. Physiol. Regul. Integr. Comp. Physiol. 297, 927-939. doi: 10.1152/ajpregu.00247.2009.-Species

Meir, J. U., Robinson, P. W., Vilchis, L. I., Kooyman, G. L., Costa, D. P., and Ponganis, P. J. (2013). Blood oxygen depletion is independent of dive function in a deep diving vertebrate, the northern elephant seal. PLoS One 8, 8-13. doi: 10.1371/journal.pone.0083248 
Meyer, W. K., Jamison, J., Richter, R., Woods, S. E., Partha, R., Kowalczyk, A., et al. (2018). Ancient convergent losses of paraoxonase 1 yield potential risks for modern marine mammals. Science 361, 591-594. doi: 10.1126/science.aap7714

Miller, N. J., Daniels, C. B., Costa, D. P., and Orgeig, S. (2004). Control of pulmonary surfactant secretion in adult California Sea lions. Biochem. Biophys. Res. Commun. 313, 727-732. doi: 10.1016/j.bbrc.2003.12.012

Miller, N. J., Daniels, C. B., Schürch, S., Schoel, W. M., and Orgeig, S. (2006). The surface activity of pulmonary surfactant from diving mammals. Respir. Physiol. Neurobiol. 150, 220-232. doi: 10.1016/j.resp.2005.03.002

Mirceta, S., Signore, A. V., Burns, J. M., Cossins, A. R., Campbell, K. L., and Berenbrink, M. (2013). Evolution of mammalian diving capacity traced by myoglobin net surface charge. Science 340:1234192. doi: 10.1126/science.1234192

Murphy, B. J., and Hochachka, P. W. (1981). Free amino acid profiles in blood during diving and recovery in the Antarctic Weddell seal. Can. J. Zool. 59, 455-459. doi: 10.1139/z81-066

Murphy, B., Zapol, W. M., and Hochachka, P. W. (1980). Metabolic activities of heart, lung, and brain during diving and recovery in the Weddell seal. J. Appl. Physiol. 48, 596-605. doi: 10.1152/jappl.1980.48.4.596

Nikinmaa, M., Pursiheimo, S., and Soitamo, A. J. (2004). Redox state regulates HIF-1 $\alpha$ and its DNA binding and phosphorylation in salmonid cells. J. Cell Sci. 117, 3201-3206. doi: 10.1242/jcs.01192

Noel, J., Wang, H., Hong, N., Tao, J.-Q., Yu, K., Sorokina, E. M., et al. (2013). PECAM-1 and caveolae form the mechanosensing complex necessary for NOX2 activation and angiogenic signaling with stopped flow in pulmonary endothelium. Am. J. Physiol. Lung Cell. Mol. Physiol. 305, L805-L818. doi: 10.1152/ajplung.00123.2013

Odden, A., Folkow, L. P., Caputa, M., Hotvedt, R., and Blix, A. S. (1999). Brain cooling in diving seals. Acta Physiol. Scand. 166, 77-78. doi: 10.1046/j. 1365-201x.1999.00536.x

Otterbein, L. E., Bach, F. H., Alam, J., Soares, M., Lu, H. T., Wysk, M., et al. (2000). Carbon monoxide has anti-inflammatory effects involving the mitogenactivated protein kinase pathway. Nat. Med. 6, 422-428. doi: 10.1038/74680

Ozaki, K. S., Kimura, S., and Murase, N. (2012). Use of carbon monoxide in minimizing ischemia/reperfusion injury in transplantation. Transplant. Rev. 26, 125-139. doi: 10.1016/j.trre.2011.01.004

Paradies, G., Petrosillo, G., Pistolese, M., Di Venosa, N., Serena, D., and Ruggiero, F. M. (1999). Lipid peroxidation and alterations to oxidative metabolism in mitochondria isolated from rat heart subjected to ischemia and reperfusion. Free Radic. Biol. Med. 27, 42-50. doi: 10.1016/S0891-5849(99)00032-5

Peck, H. E., Costa, D. P., and Crocker, D. E. (2016). Body reserves influence allocation to immune responses in capital breeding female northern elephant seals. Funct. Ecol. 30, 389-397. doi: 10.1111/1365-2435.12504

Perkins, A., Nelson, K. J., Parsonage, D., Poole, L. B., and Karplus, P. A. (2015). Peroxiredoxins: guardians against oxidative stress and modulators of peroxide Signaling. Trends Biochem. Sci. 40, 435-445. doi: 10.1016/j.tibs.2015.05.001

Ponganis, P. J. (2019). State of the art review: from the seaside to the bedside: insights from comparative diving physiology into respiratory, sleep and critical care. Thorax 0, 1-7. doi: 10.1136/thoraxjnl-2018-212136

Ponganis, P. J., Kooyman, G. L., and Castellini, M. A. (1993). Determinants of the aerobic dive limit of Weddell seals: analysis of diving metabolic rates, postdive end tidal $\mathrm{Po}_{2}$ 's, and blood and muscle oxygen stores. Physiol. Zool. 66, 732-749. doi: 10.1086/physzool.66.5.30163821

Ponganis, P. J., Kreutzer, U., Sailasuta, N., Knower, T., Hurd, R., and Jue, T. (2002). Detection of myoglobin desaturation in Mirounga angustirostris during apnea. Am. J. Physiol. Integr. Comp. Physiol. 282, R267-R272. doi: 10.1152/ajpregu.00240.2001

Ponganis, P. J., Kreutzer, U., Stockard, T. K., Lin, P.-C., Sailasuta, N., Tran, T.-K., et al. (2008). Blood flow and metabolic regulation in seal muscle during apnea. J. Exp. Biol. 211, 3323-3332. doi: 10.1242/jeb.018887

Ponganis, P. J., Meir, J. U., and Williams, C. L. (2011). In pursuit of Irving and Scholander: a review of oxygen store management in seals and penguins. J. Exp. Biol. 214, 3325-3339. doi: 10.1242/jeb.031252

Ponganis, P. J., Stockard, T. K., Levenson, D. H., Berg, L., and Baranov, E. A. (2006). Cardiac output and muscle blood flow during rest-associated apneas of elephant seals. Comp. Biochem. Physiol. A Mol. Integr. Physiol. 144, 105-111. doi: 10.1016/j.cbpa.2006.02.009

Pryor, J. M., Waters, C. A., Aza, A., Asagoshi, K., Strom, C., Mieczkowski, P. A., et al. (2015). Essential role for polymerase specialization in cellular nonhomologous end joining. Proc. Natl. Acad. Sci. USA 112, E4537-E4545. doi: $10.1073 /$ pnas. 1505805112
Qvist, J., Hill, R. D., Schneider, R. C., Falke, K. J., Liggins, G. C., Guppy, M., et al. (1986). Hemoglobin concentrations and blood gas tensions of free-diving Weddell seals. J. Appl. Physiol. 61, 1560-1569. doi: 10.1152/jappl.1986.61.4.1560

Qvist, J., Weber, R. E., and Zapol, W. M. (1981). Oxygen equilibrium properties of blood and hemoglobin of fetal and adult Weddell seals. J. Appl. Physiol. 50, 999-1005. doi: 10.1152/jappl.1981.50.5.999

Radi, R., Peluffo, G., Alvarez, M. N., Naviliat, M., and Cayota, A. (2001). Unraveling peroxynitrite formation in biological systems. Free Radic. Biol. Med. 30, 463-488. doi: 10.1016/S0891-5849(00)00373-7

Ridgway, S. H., Carder, D. A., and Clark, W. (1975). Conditioned bradycardia in the sea lion Zalophus californianus. Nature 256, 37-38. doi: 10.1038/256037a0

Righetti, B. P. H., Simões-Lopes, P. C., Uhart, M. M., and Wilhelm Filho, D. (2014). Relating diving behavior and antioxidant status: insights from oxidative stress biomarkers in the blood of two distinct divers, Mirounga leonina and Arctocephalus australis. Comp. Biochem. Physiol. A Mol. Integr. Physiol. 173, 1-6. doi: 10.1016/j.cbpa.2014.02.017

Robinson, P. W., Costa, D. P., Crocker, D. E., Gallo-Reynoso, J. P., Champagne, C. D., Fowler, M. A., et al. (2012). Foraging behavior and success of a mesopelagic predator in the Northeast Pacific Ocean: insights from a data-rich species, the northern elephant seal. PLoS One 7:e36728. doi: 10.1371/journal.pone.0036728

Saikumar, P., Dong, Z., Weinberg, J. M., and Venkatachalam, M. A. (1998). Mechanisms of cell death in hypoxia/reoxygenation injury. Oncogene 17, 3341-3349. doi: 10.1038/sj.onc.1202579

Sakamoto, A., Ohnishi, S. T., Ohnishi, T., and Ogawa, R. (1991). Relationship between free radical production and lipid peroxidation during ischemiareperfusion injury in the rat brain. Brain Res. 554, 186-192.

Salvadori, M., Rosso, G., and Bertoni, E. (2015). Update on ischemia-reperfusion injury in kidney transplantation: pathogenesis and treatment. World J. Transplant. 5, 52-67. doi: 10.5500/wjt.v5.i2.52

Schneuer, M., Flachsbarth, S., Czech-Damal, N. U., Folkow, L. P., Siebert, U., and Burmester, T. (2012). Neuroglobin of seals and whales: evidence for a divergent role in the diving brain. Neuroscience 223, 35-44. doi: 10.1016/j. neuroscience.2012.07.052

Semenza, G. L. (2008). Regulation of oxygen homeostasis by hypoxia-inducible factor 1. Physiology 24, 97-106. doi: 10.1152/physiol.00045.2008

Sendoel, A., and Hengartner, M. O. (2014). Apoptotic cell death under hypoxia. Physiology 29, 168-176. doi: 10.1152/physiol.00016.2013

Shaffer, S. A., Costa, D. P., Williams, T. M., and Ridgway, S. H. (1997). Diving and swimming performance of white whales, Delphinapterus leucas: an assessment of plasma lactate and blood gas levels and respiratory rates. J. Exp. Biol. 200, 3091-3099. Available at: http://www.ncbi.nlm.nih.gov/pubmed/9364017

Soitamo, A. J., Råbergh, C. M. I., Gassmann, M., Sistonen, L., and Nikinmaa, M. (2001). Characterization of a hypoxia-inducible factor (HIF-1a) from rainbow trout. J. Biol. Chem. 276, 19699-19705. doi: 10.1074/jbc.M009057200

Soñanez-Organis, J. G., Vázquez-Medina, J. P., Crocker, D. E., and Ortiz, R. M. (2014). Prolonged fasting activates HIF-1a, $-2 \mathrm{a}$, and $-3 \mathrm{a}$ in a tissue-specific manner in northern elephant seal pups. Gene 526, 155-163. doi: 10.1016/j. gene.2013.05.004.Prolonged

Soñanez-Organis, J. G., Vázquez-Medina, J. P., Zenteno-Savín, T., Aguilar, A., Crocker, D. E., and Ortiz, R. M. (2012). Prolonged fasting increases purine recycling in post-weaned northern elephant seals. J. Exp. Biol. 215, 1448-1455. doi: $10.1242 /$ jeb.067173

Spragg, R. G., Ponganis, P. J., Marsh, J. J., Rau, G. A., and Bernhard, W. (2004). Surfactant from diving aquatic mammals. J. Appl. Physiol. 96, 1626-1632. doi: 10.1152/japplphysiol.00898.2003

Stockard, T. K., Levenson, D. H., Berg, L., Fransioli, J. R., Baranov, E. A., and Ponganis, P. J. (2007). Blood oxygen depletion during rest-associated apneas of northern elephant seals (Mirounga angustirostris). J. Exp. Biol. 210, 2607-2617. doi: 10.1242/jeb.008078

Suzuki, Y. J., Forman, H. J., and Sevanian, A. (1997). Oxidants as stimulators of signal transduction. Free Radic. Biol. Med. 22, 269-285. doi: 10.1016/ S0891-5849(96)00275-4

Suzuki, M., Vázquez-Medina, J. P., Viscarra, J. A., Soñanez-organis, J. G., Crocker, D. E., and Ortiz, R. M. (2013). Activation of systemic, but not local, renin-angiotensin system is associated with upregulation of TNF- $\alpha$ during prolonged fasting in northern elephant seal pups. J. Exp. Biol. 216, 3215-3221. doi: 10.1242/jeb.085225

Szabó, C. (1996). The pathophysiological role of peroxynitrite in shock, inflammation, and ischemia-reperfusion injury. Shock 6, 79-88. doi: 10.1097/00024382-199608000-00001 
Thielmann, M., Kottenberg, E., Kleinbongard, P., Wendt, D., Gedik, N., Pasa, S., et al. (2013). Cardioprotective and prognostic effects of remote ischaemic preconditioning in patients undergoing coronary artery bypass surgery: a single-centre randomised, double-blind, controlled trial. Lancet 382, 597-604. doi: 10.1016/S0140-6736(13)61450-6

Thornton, S. J., Spielman, D. M., Pelc, N. J., Block, W. F., Crocker, D. E., Costa, D. P., et al. (2001). Effects of forced diving on the spleen and hepatic sinus in northern elephant seal pups. Proc. Natl. Acad. Sci. USA 98, 9413-9418. doi: 10.1073/pnas. 151192098

Tian, R., Wang, Z., Niu, X., Zhou, K., Xu, S., and Yang, G. (2016). Evolutionary genetics of hypoxia tolerance in cetaceans during diving. Genome Biol. Evol. 8, 827-839. doi: 10.1093/gbe/evw037

Tian, R., Yin, D., Liu, Y., Seim, I., Xu, S., and Yang, G. (2017). Adaptive evolution of energy metabolism-related genes in hypoxia-tolerant mammals. Front. Genet. 8, 1-11. doi: 10.3389/fgene.2017.00205

Tift, M. S., Hückstädt, L. A., and Ponganis, P. J. (2018). Anterior vena caval oxygen profiles in a deep-diving California Sea lion: arteriovenous shunts, a central venous oxygen store and oxygenation during lung collapse. J. Exp. Biol. 221:jeb174235. doi: 10.1242/jeb.163428

Tift, M. S., Ponganis, P. J., and Crocker, D. E. (2014). Elevated carboxyhemoglobin in a marine mammal, the northern elephant seal. J. Exp. Biol. 217, 1752-1757. doi: $10.1242 /$ jeb.100677

Tojo, T., Ushio-Fukai, M., Yamaoka-Tojo, M., Ikeda, S., Patrushev, N., and Alexander, R. W. (2005). Role of gp91phox (Nox2)-containing NAD(P)H oxidase in angiogenesis in response to Hindlimb ischemia. Circulation 111, 2347-2355. doi: 10.1161/01.CIR.0000164261.62586.14

Vázquez-Medina, J. P., Allen, K., and Hindle, A. G. (2018). Seal endothelial cells: a comparative model to study natural tolerance to ischemia/reperfusion. FASEB J. 32, 859.8.

Vázquez-Medina, J. P., Crocker, D. E., Forman, H. J., and Ortiz, R. M. (2010). Prolonged fasting does not increase oxidative damage or inflammation in postweaned northern elephant seal pups. J. Exp. Biol. 213, 2524-2530. doi: $10.1242 /$ jeb.041335

Vázquez-Medina, J. P., Olguín-Monroy, N. O., Maldonado, P. D., Santamaría, A., Königsberg, M., Elsner, R., et al. (2011a). Maturation increases superoxide radical production without increasing oxidative damage in the skeletal muscle of hooded seals (Cystophora cristata). Can. J. Zool. 89, 206-212. doi: 10.1139/ Z10-107

Vázquez-Medina, J. P., Soñanez-Organis, J. G., Burns, J. M., Zenteno-Savín, T., and Ortiz, R. M. (2011b). Antioxidant capacity develops with maturation in the deep-diving hooded seal. J. Exp. Biol. 214, 2903-2910. doi: 10.1242/ jeb.057935

Vázquez-Medina, J. P., Zenteno-Savín, T., and Elsner, R. (2006). Antioxidant enzymes in ringed seal tissues: potential protection against dive-associated ischemia/reperfusion. Comp. Biochem. Physiol. C Toxicol. Pharmacol. 142, 198-204. doi: 10.1016/j.cbpc.2005.09.004

Vázquez-Medina, J. P., Zenteno-Savín, T., and Elsner, R. (2007). Glutathione protection against dive-associated ischemia/reperfusion in ringed seal tissues. J. Exp. Mar. Biol. Ecol. 345, 110-118. doi: 10.1016/j.jembe.2007.02.003

Vázquez-Medina, J. P., Zenteno-Savín, T., Elsner, R., and Ortiz, R. M. (2012). Coping with physiological oxidative stress: a review of antioxidant strategies in seals. J. Comp. Physiol. B Biochem. Syst. Environ. Physiol. 182, 741-750. doi: $10.1007 /$ s00360-012-0652-0

Vázquez-Medina, J. P., Zenteno-Savín, T., Forman, H. J., Crocker, D. E., and Ortiz, R. M. (2011c). Prolonged fasting increases glutathione biosynthesis in postweaned northern elephant seals. J. Exp. Biol. 214, 1294-1299. doi: 10.1242/jeb.054320

Vázquez-Medina, J. P., Zenteno-Savín, T., Tift, M. S., Forman, H. J., Crocker, D. E., and Ortiz, R. M. (2011d). Apnea stimulates the adaptive response to oxidative stress in elephant seal pups. J. Exp. Biol. 214, 4193-4200. doi: 10.1242/jeb.063644

Wang, Y., Gao, L., Wu, S.-Y., and Qin, S. (2018). Low-dose 4-hydroxy-2-nonenal (HNE) reperfusion therapy displays cardioprotective effects in mice after myocardial infarction that are abrogated by Genipin. Med. Sci. Monit. 24, 3702-3709. doi: 10.12659/MSM.910494

Wang, G. L., Jiang, B.-H., Rue, E. A., and Semenza, G. L. (1995). Hypoxiainducible factor 1 is a basic-helix-loop-helix-PAS heterodimer regulated by cellular $\mathrm{O}_{2}$ tension. Proc. Natl. Acad. Sci. USA 92, 5510-5514.
Weidemann, A., and Johnson, R. S. (2008). Biology of HIF-1a. Cell Death Differ. 15, 621-627. doi: 10.1038/cdd.2008.12

Wilhelm Filho, D., Sell, F., Ribeiro, L., Ghislandi, M., Carrasquedo, F., Fraga, C. G., et al. (2002). Comparison between the antioxidant status of terrestrial and diving mammals. Comp. Biochem. Physiol. A Mol. Integr. Physiol. 133, 885-892. doi: 10.1016/S1095-6433(02)00253-2

Williams, T. M., Fuiman, L. A., Kendall, T., Berry, P., Richter, B., Noren, S. R., et al. (2015). Exercise at depth alters bradycardia and incidence of cardiac anomalies in deep-diving marine mammals. Nat. Commun. 6, 1-9. doi: 10.1038/ncomms7055

Williams, T. M., Haun, J. E., and Friedl, W. A. (1999). The diving physiology of bottlenose dolphins (Tursiops truncatus). III. Thermoregulation at depth. J. Exp. Biol. 202, 2739-2748. Available at: http://www.ncbi.nlm.nih.gov/ pubmed/10504312

Williams, T. M., Zavanelli, M., Miller, M. A., Goldbeck, R. A., Morledge, M., Casper, D., et al. (2008). Running, swimming and diving modifies neuroprotecting globins in the mammalian brain. Proc. R. Soc. B 275, 751-758. doi: 10.1098/ rspb.2007.1484

Wright, T. J., and Davis, R. W. (2015). Myoglobin oxygen affinity in aquatic and terrestrial birds and mammals. J. Exp. Biol. 218, 2180-2189. doi: 10.1242/ jeb.119321

Yellon, D. M., and Hausenloy, D. H. (2007). Myocardial reperfusion injury. N. Engl. J. Med. 357, 1121-1135. doi: 10.1056/NEJMra071667

Yim, H.-S., Cho, Y. S., Guang, X., Kang, S. G., Jeong, J.-Y., Cha, S.-S., et al. (2014). Minke whale genome and aquatic adaptation in cetaceans. Nat. Genet. 46, 88-94. doi: 10.1038/ng.2835

Zapol, W. M., Liggins, G. C., Schneider, R. C., Qvist, J., Snider, M. T., Creasy, R. K., et al. (1979). Regional blood flow during simulated diving in the conscious Weddell seal. J. Appl. Physiol. 47, 968-973. doi: 10.1152/ jappl.1979.47.5.968

Zenteno-Savín, T., Castellini, M. A., Rea, L. D., and Fadely, B. S. (1997). Plasma haptoglobin levels in threatened Alaskan pinniped populations. J. Wildl. Dis. 33, 64-71. doi: 10.7589/0090-3558-33.1.64

Zenteno-Savín, T., Clayton-Hernández, E., and Elsner, R. (2002). Diving seals: are they a model for coping with oxidative stress? Comp. Biochem. Physiol. C Toxicol. Pharmacol. C 133, 527-536. doi: 10.1016/S15320456(02)00075-3

Zenteno-Savin, T., St. Leger, J., and Ponganis, P. J. (2010). Hypoxemic and ischemic tolerance in emperor penguins. Comp. Biochem. Physiol. C Toxicol. Pharmacol. 152, 18-23. doi: 10.1016/j.cbpc.2010.02.007

Zenteno-Savin, T., Vázquez-Medina, J. P., Cantu-Medellin, N., Ponganis, P. J., and Elsner, R. (2011). "Ischemia/reperfusion in diving birds and mammals: how they avoid oxidative damage" in Oxidative stress in aquatic ecosystems. eds. D. Abele, J. P. Vázquez-Medina, and T. Zenteno-Savín (Blackwell Publishing Ltd.).

Zhang, Y., Sano, M., Shinmura, K., Tamaki, K., Katsumata, Y., Matsuhashi, T., et al. (2010). 4-Hydroxy-2-nonenal protects against cardiac ischemia-reperfusion injury via the Nrf2-dependent pathway. J. Mol. Cell. Cardiol. 49, 576-586. doi: 10.1016/j.yjmcc.2010.05.011

Zhou, X., Sun, D., Guang, X., Ma, S., Fang, X., Mariotti, M., et al. (2018). Molecular footprints of aquatic adaptation including bone mass changes in cetaceans. Genome Biol. Evol. 10, 967-975. doi: 10.1093/gbe/evy062

Zhu, K., Ge, D., Wen, Z., Xia, L., and Yang, Q. (2018). Evolutionary genetics of hypoxia and cold tolerance in mammals. J. Mol. Evol. 86, 618-634. doi: 10.1007/s00239-018-9870-8

Conflict of Interest: The authors declare that the research was conducted in the absence of any commercial or financial relationships that could be construed as a potential conflict of interest.

Copyright (c) 2019 Allen and Vázquez-Medina. This is an open-access article distributed under the terms of the Creative Commons Attribution License (CC $B Y$ ). The use, distribution or reproduction in other forums is permitted, provided the original author(s) and the copyright owner(s) are credited and that the original publication in this journal is cited, in accordance with accepted academic practice. No use, distribution or reproduction is permitted which does not comply with these terms. 